\title{
The Fuel Temperature Variation Used as Fuel Diesel-Palm Oil Mixtures under Constant Fuel Consumption
}

\author{
Charalampos Arapatsakos, Dimitrios Christoforidis and Styliani Gkavaki \\ Department of Production and Management Engineering, Democritus University of Thrace, Xanthi 67100, Greece
}

Received: October 26, 2011 / Accepted: December 19, 2011 / Published: April 20, 2012.

\begin{abstract}
This work examines the effect of fuel temperature in the gas emissions that is used in a four-stroke diesel engine under maximum constant fuel consumption. The fuel temperatures that were used are $20{ }^{\circ} \mathrm{C}, 30{ }^{\circ} \mathrm{C}, 40{ }^{\circ} \mathrm{C}, 50{ }^{\circ} \mathrm{C}, 60{ }^{\circ} \mathrm{C}, 70{ }^{\circ} \mathrm{C}$ and $80{ }^{\circ} \mathrm{C}$. The engine was functioned under full load condition when it was using different mixtures of diesel-palm oil as fuel. For those fuel temperatures and for any mixture of fuel the gas emissions of carbon monoxide (CO), hydrocarbons (HC), nitrogen monoxide (NO) and rotate speed of engine are examined.
\end{abstract}

Key words: Gas emissions, fuel temperature, palm oil.

\section{Introduction}

One of the most renewable energy sources is biomass. Biomass is called every material that is produced by living organisms on a renewable basis, such as plants, animals and microorganisms. Biomass is an energy source that is constantly renewed because of photosynthesis. In photosynthesis, solar energy is bound and converted to chemical. During the combustion of biomass, solar energy becomes bound to heat and $\mathrm{CO}_{2}$ (that is produced) goes back to the atmosphere and minerals included in the ash enrich the soil with nutrients. Biomass was the first fuel that has been used from the human being. Nowadays, it covers about $4 \%$ of total energy consumed in the USA and $45 \%$ of renewable energy sources [1-3].

The most obvious source of biomass is trees. Woodfuel can be derived from conventional forestry practice such as thinning and trimming as part of sustainable management of woodland to ensure the production of high quality timber for construction,

Corresponding author: Charalampos Arapatsakos, Ph.D., research fields: biofuels, gas emissions, engines, environment. E-mail: xarapat@agro.duth.gr. joinery and wood products and optimization of biodiversity. It can also be derived from tree surgery operations and the management of parks, gardens and transport corridors. The types of biomass for energy that are produced in the forest are firewood, charcoal, logging debris and cleaning duties which need to be removed so that not to be combustible materials on fire. Other types of biomass that can be used for energy production are various materials of vegetable origin, such as agricultural residues (i.e. straw) and sub products (i.e. olive pits) and energy crops, waste materials of animal origin from animal husbandry and fishery remains and by-products waste and urban waste etc.. Agricultural residues are in a wide variety of types. The most significant division is between those residues that are predominantly dry, such as straw and those that are wet such as animal slurry.

All these forms of biomass are an important renewable source, which is produced in large quantities and its energy use can have multiple environmental benefits [1, 3-5].

Biomass can be used for the production of liquid fuels (known as biofuels) as well. Lately, these are used 
in transport in many countries (France, Germany, Italy, USA etc.) [6].

Biodiesel is also produced from oil crops (soy, canola, sunflower), animal fat, offal and waste.

There are some advantages that make biomass an attractive source of energy. These are:

(1) The burning of biomass has a zero balance of carbon dioxide $\left(\mathrm{CO}_{2}\right)$. It does not contribute to greenhouse due to the fact that the amounts of carbon dioxide $\left(\mathrm{CO}_{2}\right)$ released during the burning of biomass bound again by plants to create biomass;

(2) The minimal presence of sulfur in biomass contributes significantly to the reduction of sulful dioxide emissions $\left(\mathrm{SO}_{2}\right)$, which is responsible for the acid rain;

(3) Since biomass is domestic source of energy, it contributes significantly to the reduction of import fuels dependency and improves the trade balance in securing energy supply and saving foreign exchange;

(4) The use of biomass energy in an area increases the employment in rural areas with the use of alternative crops (various rape, sorghum, and reed), the creation of alternative markets for traditional crops (sunflower etc.) and the retention of the population in their homes, thus contributing to socioeconomic development in the region. Studies have shown that the production of liquid biofuels has positive effects on employment in both rural and industrial area.

An example of biodiesel is palm oil. Palm oil is produced from the palm tree Elaeis guineensis. The fruit of the palm is the only one that can lead to the preparation of two types of oil, oil from the flesh of the fruit and oil from the fruit kernels. Virgin palm oil is rich in carotenoids (provitamin A), tocotrienols and tocopherols (vitamin E) and contains no trans fatty acids. Palm oil is often confused with oil that is produced from the core of the fruit of the palm, but in reality its composition differs. The color of palm oil is reddish because it contains high percentage of beta carotene. It can be used as cooking oil and in the manufacture of margarine as well. It is also included as an ingredient in many processed formulations [1, 2, 5-8].

The arising question is how a four-stroke diesel engine behaves on both sides of pollutants and operation, when it uses fuel mixtures diesel-palm oil in different fuel temperatures, functioning the engine under max constant fuel consumption.

\section{Instrumentation}

Specifically, it has been used as fuel mixtures of diesel-palmoil (diesel, diesel-5\% palmoil, diesel-10\% palmoil, diesel-20\% palmoil, diesel-30\% palmoil, diesel-40\% palmoil, diesel-50\% palmoil, diesel-60\% palmoil, diesel-70\% palmoil, diesel-80\% palmoil, diesel-90\% palmoil, $100 \%$ palmoil) at different temperatures: $20{ }^{\circ} \mathrm{C}, 30{ }^{\circ} \mathrm{C}, 40{ }^{\circ} \mathrm{C}, 50{ }^{\circ} \mathrm{C}, 60{ }^{\circ} \mathrm{C}, 70{ }^{\circ} \mathrm{C}$ and $80{ }^{\circ} \mathrm{C}$ in a four-stroke air cooled diesel engine, named Ruggerini type RD-80, volume 377cc with one cylinder and power $8.2 \mathrm{hp} / 3,000 \mathrm{rpm}$. The engine was connected with a centrifugal water pump. The engine was functioned under maximum constantly fuel consumption.

During the experiments, the following have been measured:

- the $\mathrm{CO} \%$;

- the HC (ppm);

- the NO (ppm);

- the engine rpm.

The measurement of rounds/min of the engine was made by a portable tachometer (digital photo/contact tachometer) named LTLutron DT-2236. Smoke was measured by a specifically measurement device named SMOKE MODULE EXHAUST GAS ANALYZER MOD 9010/M, which has been connected to a PC unit. The $\mathrm{CO}$ and $\mathrm{HC}$ emissions have been measured by HORIBA Analyzer MEXA-324 GE. The NO emissions were measured by a Single GAS Analyser SGA92-NO (Fig. 1).

\section{Results and Discussion}

The experimental results are shown in Figs. 2-29. 


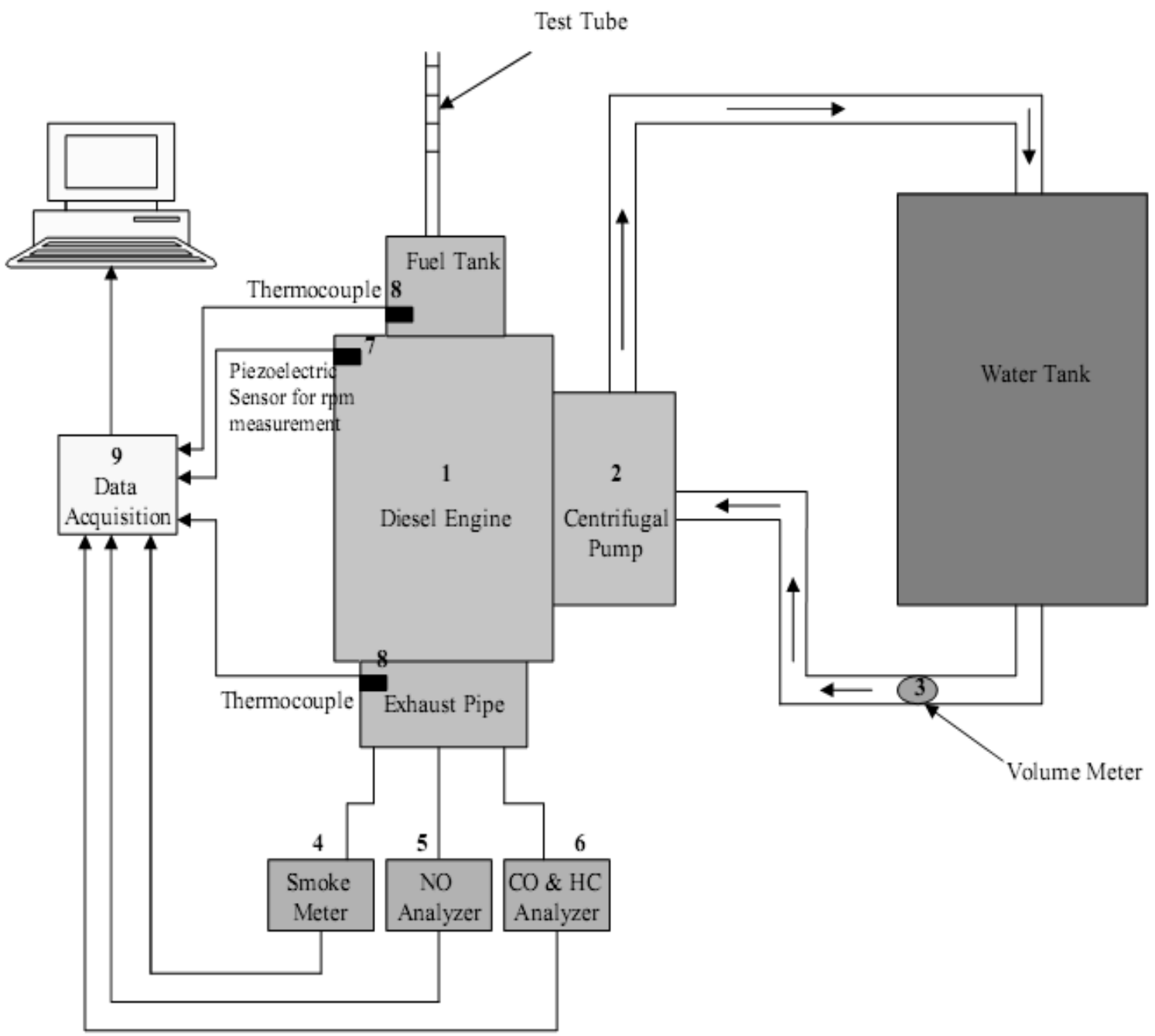

Fig. 1 Experimental layout.

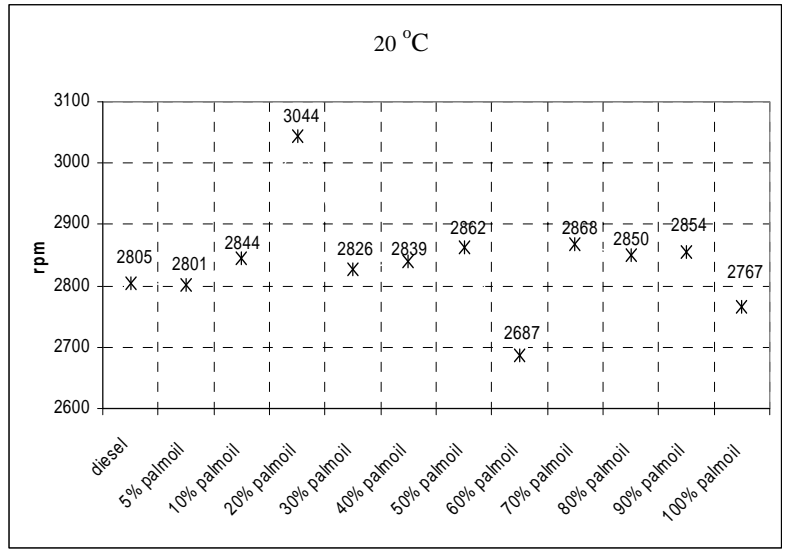

Fig. 2 The variation of $\mathrm{rpm}$ when using mixtures of diesel-palm oil as fuel on $20^{\circ} \mathrm{C}$ fuel temperature, under max constant fuel consumption.

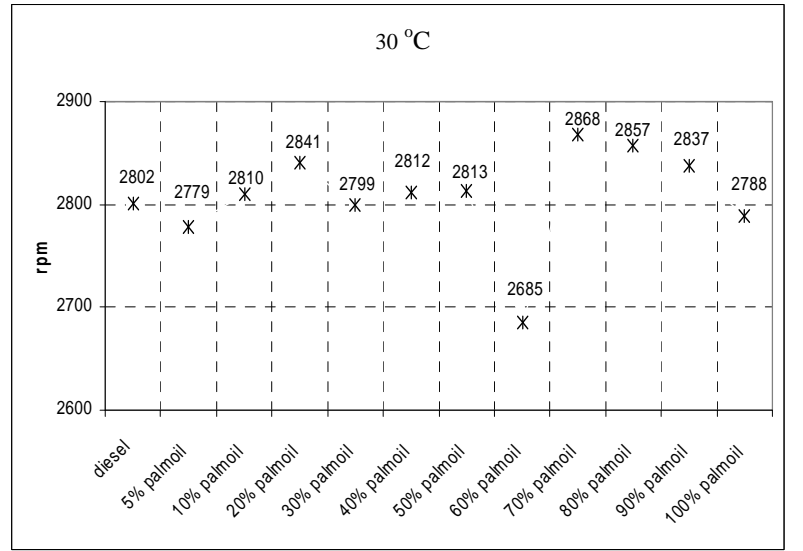

Fig. 3 The variation of rpm when using mixtures of diesel-palm oil as fuel on $30{ }^{\circ} \mathrm{C}$ fuel temperature, under max constant fuel consumption. 


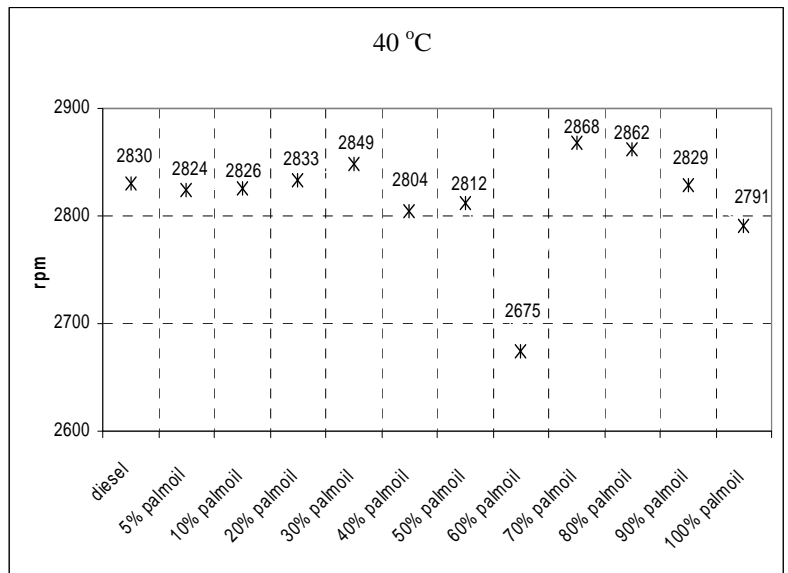

Fig. 4 The variation of $\mathrm{rpm}$ when using mixtures of diesel-palm oil as fuel on $40{ }^{\circ} \mathrm{C}$ fuel temperature, under max constant fuel consumption.

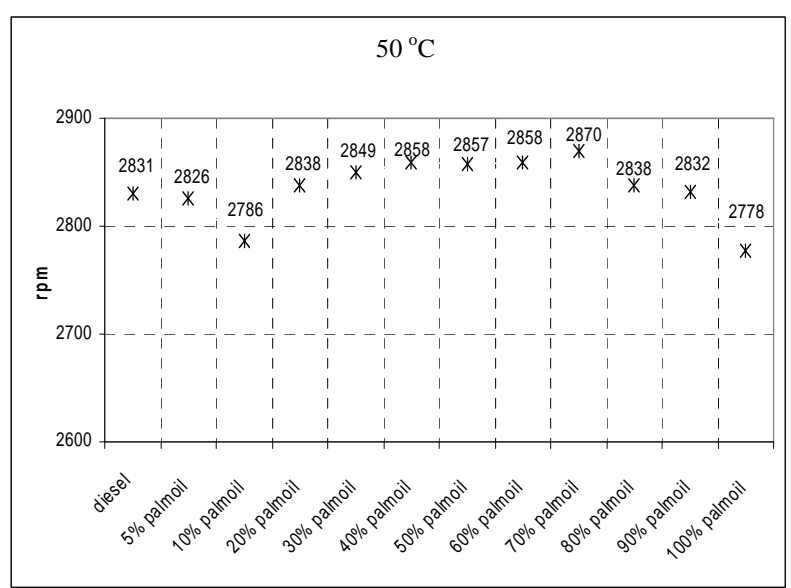

Fig. 5 The variation of $\mathbf{r p m}$ when using mixtures of diesel-palm oil as fuel on $50{ }^{\circ} \mathrm{C}$ fuel temperature, under max constant fuel consumption.

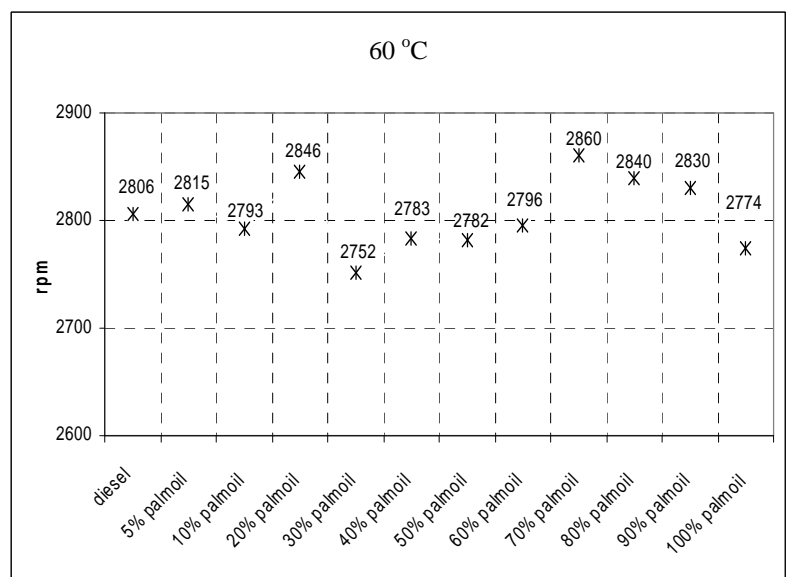

Fig. 6 The variation of rpm when using mixtures of diesel-palm oil as fuel on $60^{\circ} \mathrm{C}$ fuel temperature, under max constant fuel consumption.

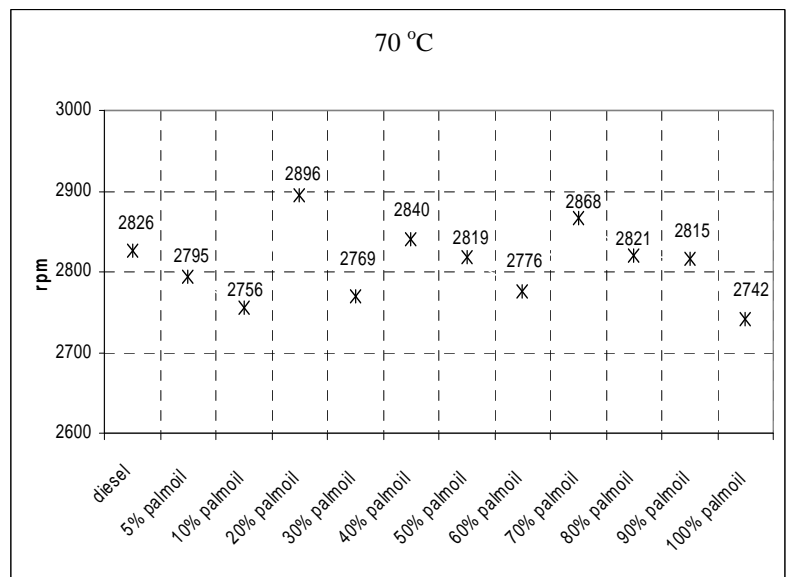

Fig. 7 The variation of $\mathbf{r p m}$ when using mixtures of diesel-palm oil as fuel on $70{ }^{\circ} \mathrm{C}$ fuel temperature, under max constant fuel consumption.

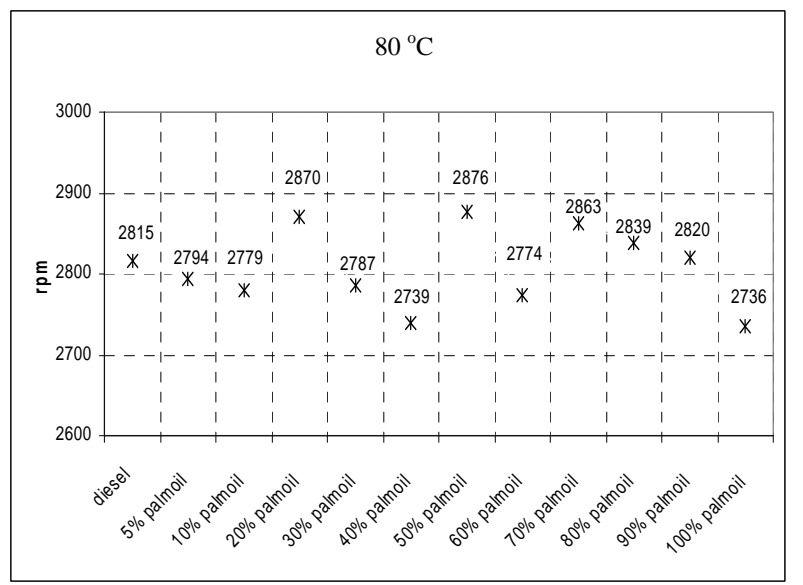

Fig. 8 The variation of $\mathbf{r p m}$ when using mixtures of diesel-palm oil as fuel on $80{ }^{\circ} \mathrm{C}$ fuel temperature, under max constant fuel consumption.

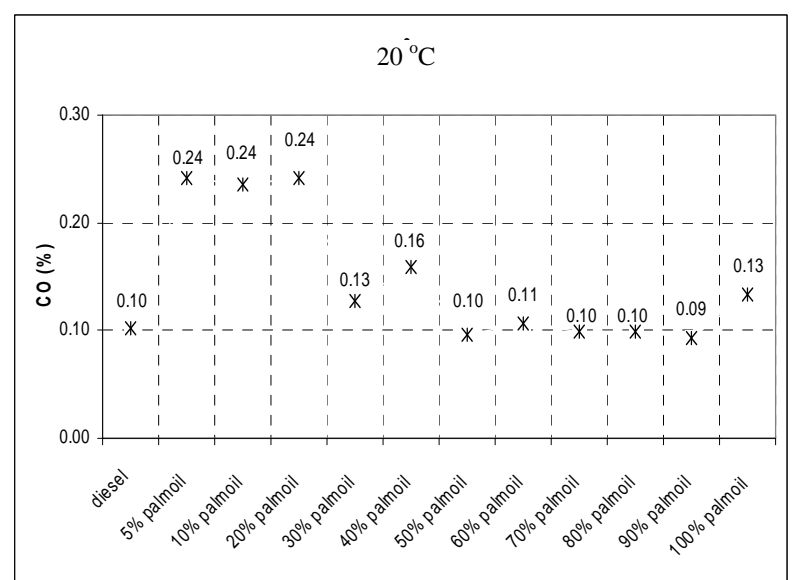

Fig. 9 The variation of $\mathrm{CO}$ when using mixtures of diesel-palm oil as fuel on $20{ }^{\circ} \mathrm{C}$ fuel temperature, under max constant fuel consumption. 

under Constant Fuel Consumption

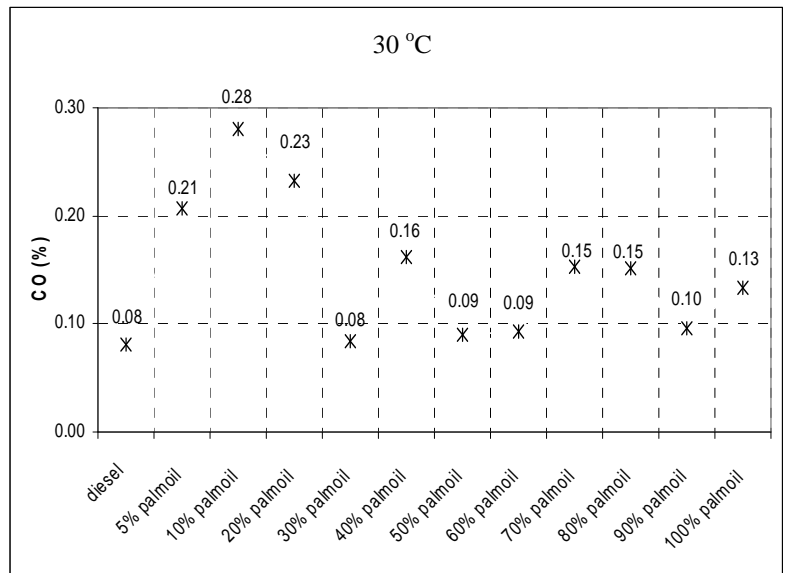

Fig. 10 The variation of $\mathrm{CO}$ when using mixtures of diesel-palm oil as fuel on $30^{\circ} \mathrm{C}$ fuel temperature, under max constant fuel consumption.

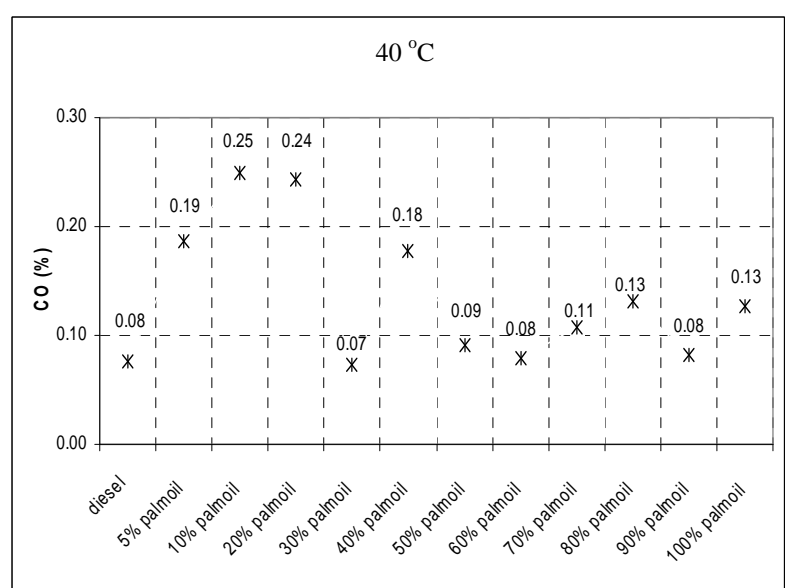

Fig. 11 The variation of $\mathrm{CO}$ when using mixtures of diesel-palm oil as fuel on $40{ }^{\circ} \mathrm{C}$ fuel temperature, under max constant fuel consumption.

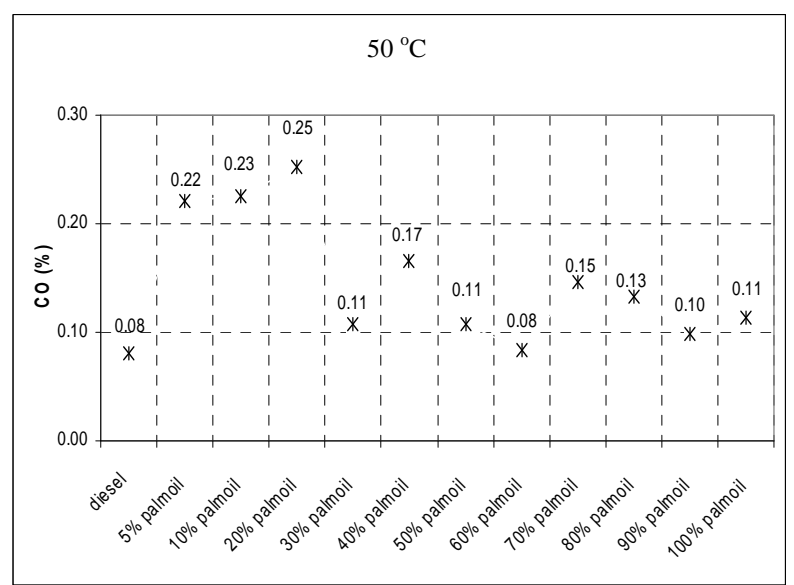

Fig. 12 The variation of $\mathrm{CO}$ when using mixtures of diesel-palm oil as fuel on $50{ }^{\circ} \mathrm{C}$ fuel temperature, under max constant fuel consumption.

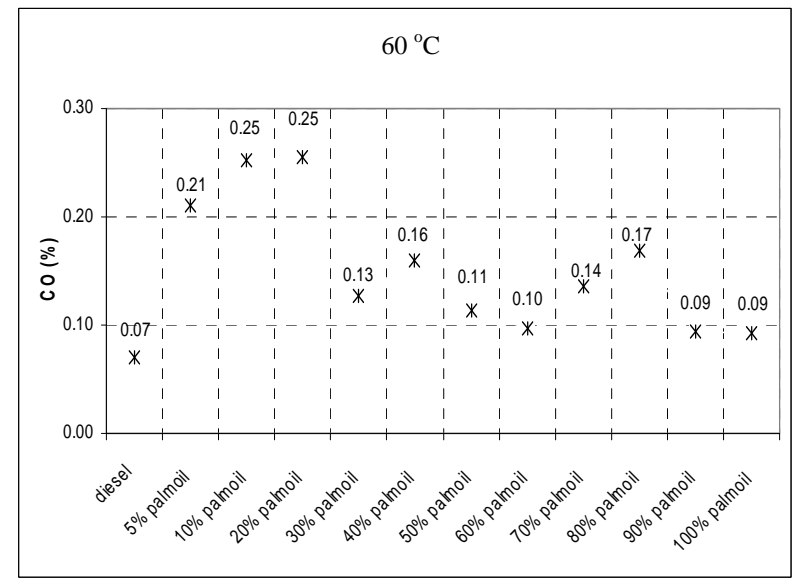

Fig. 13 The variation of $\mathrm{CO}$ when using mixtures of diesel-palm oil as fuel on $60{ }^{\circ} \mathrm{C}$ fuel temperature, under max constant fuel consumption.

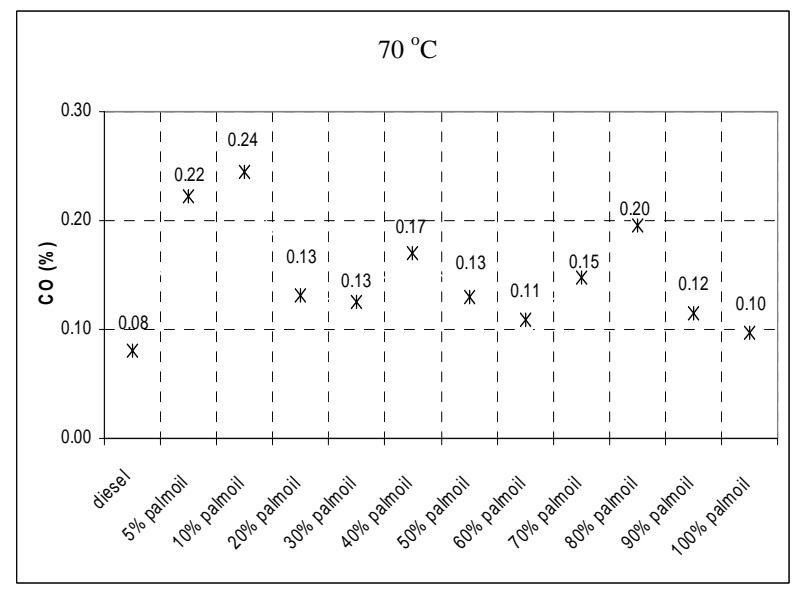

Fig. 14 The variation of $\mathrm{CO}$ when using mixtures of diesel-palm oil as fuel on $70^{\circ} \mathrm{C}$ fuel temperature, under max constant fuel consumption.

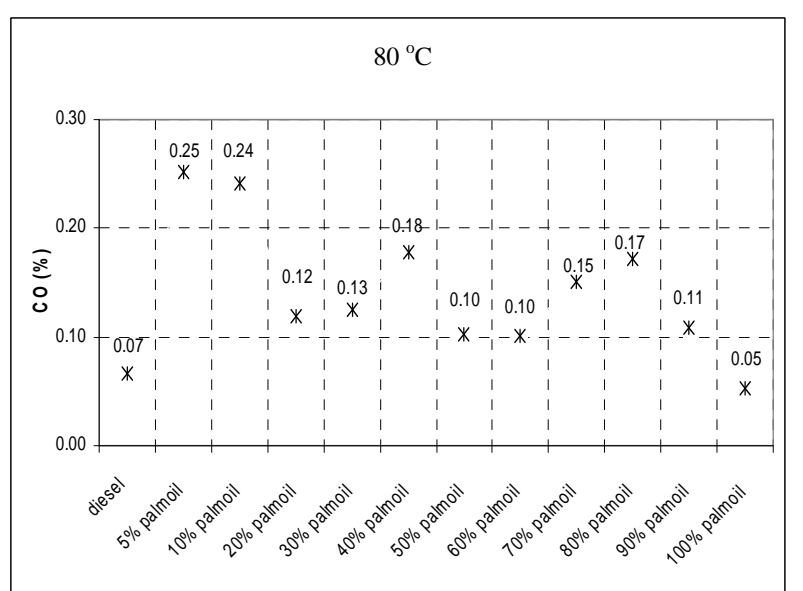

Fig. 15 The variation of $\mathrm{CO}$ when using mixtures of diesel-palm oil as fuel on $80^{\circ} \mathrm{C}$ fuel temperature, under max constant fuel consumption. 


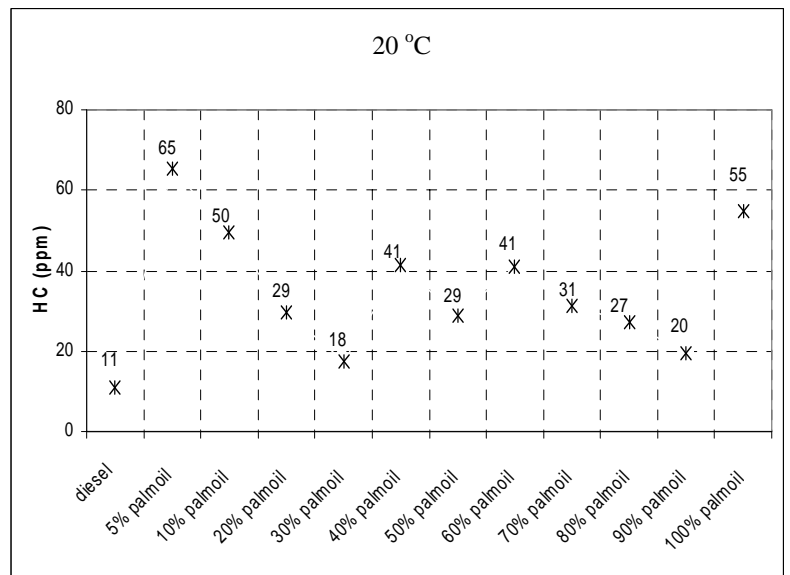

Fig. 16 The variation of $\mathrm{HC}$ when using mixtures of diesel-palm oil as fuel on $20^{\circ} \mathrm{C}$ fuel temperature, under max constant fuel consumption.

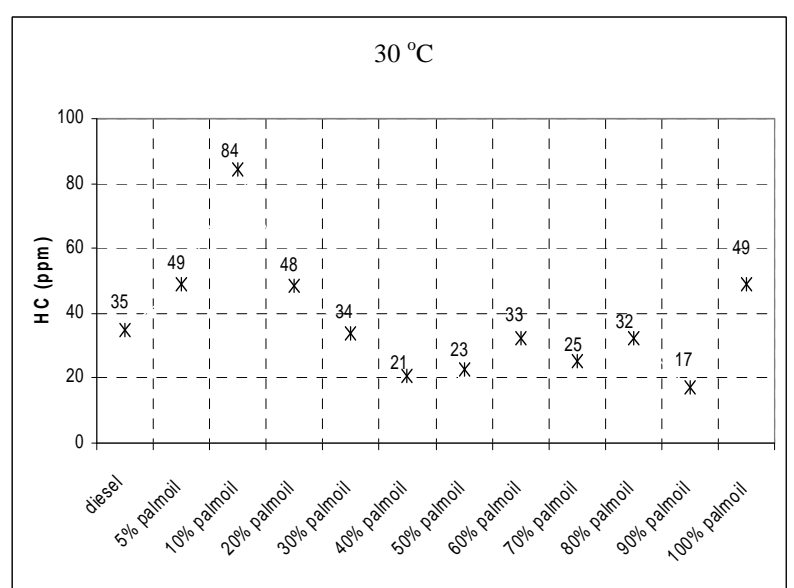

Fig. 17 The variation of $\mathrm{HC}$ when using mixtures of diesel-palm oil as fuel on $30{ }^{\circ} \mathrm{C}$ fuel temperature, under max constant fuel consumption.

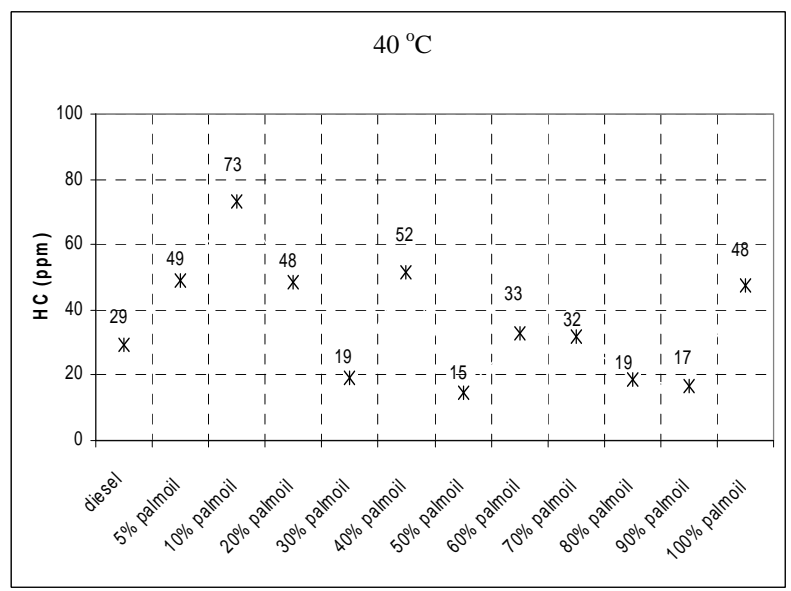

Fig. 18 The variation of $\mathrm{HC}$ when using mixtures of diesel-palm oil as fuel on $40^{\circ} \mathrm{C}$ fuel temperature, under max constant fuel consumption.

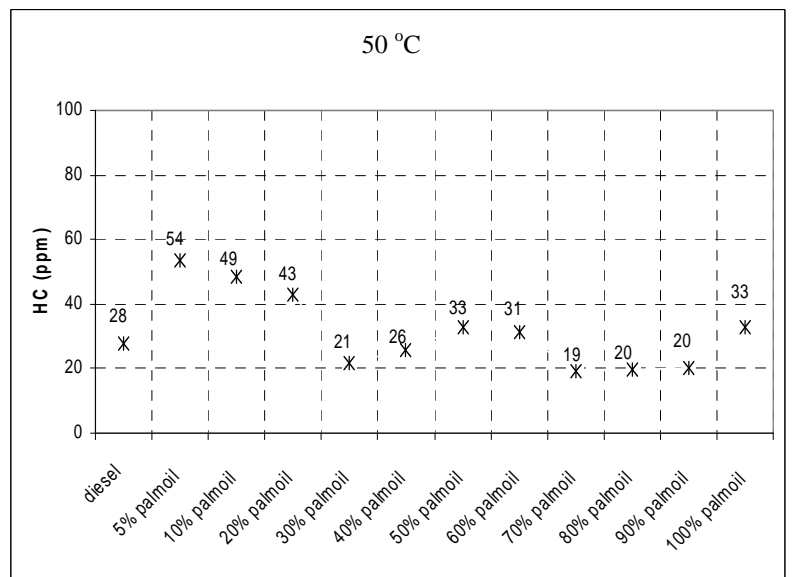

Fig. 19 The variation of $\mathrm{HC}$ when using mixtures of diesel-palm oil as fuel on $50{ }^{\circ} \mathrm{C}$ fuel temperature, under max constant fuel consumption.

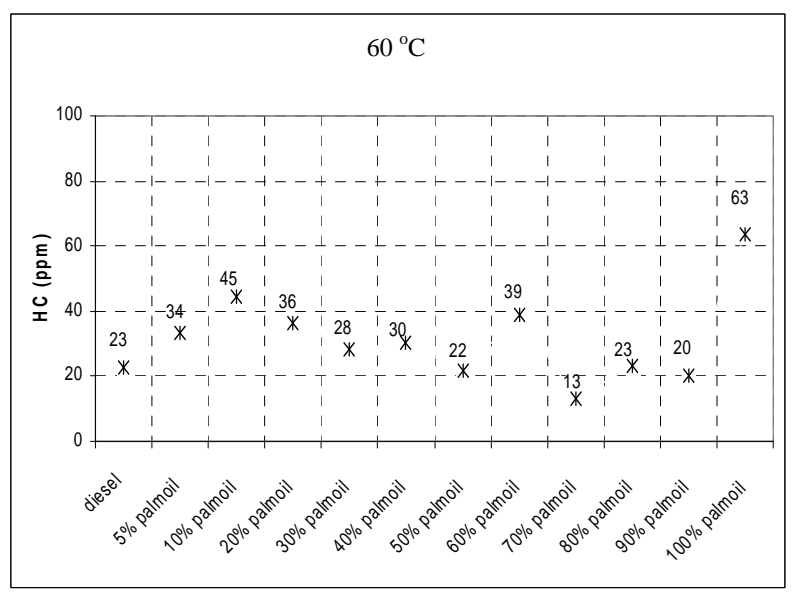

Fig. 20 The variation of $\mathrm{HC}$ when using mixtures of diesel-palm oil as fuel on $60^{\circ} \mathrm{C}$ fuel temperature, under max constant fuel consumption.

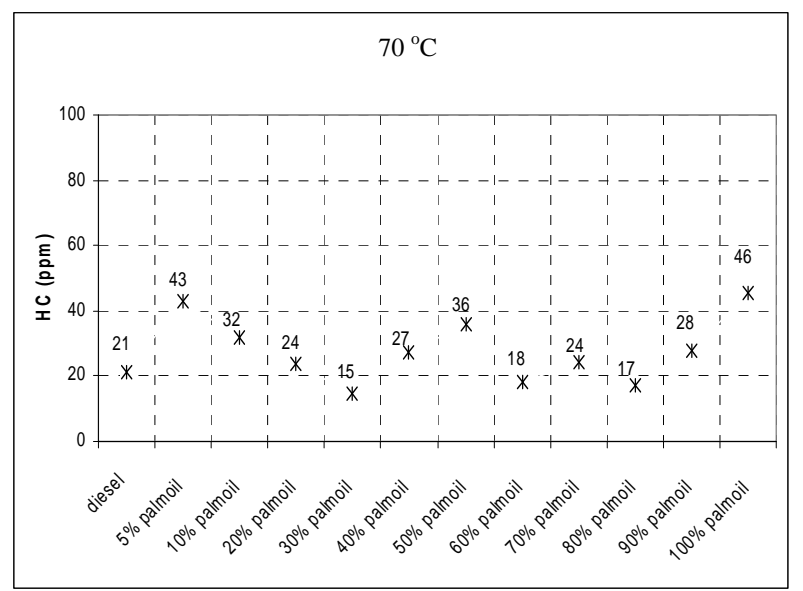

Fig. 21 The variation of $\mathrm{HC}$ when using mixtures of diesel-palm oil as fuel on $70^{\circ} \mathrm{C}$ fuel temperature, under max constant fuel consumption. 


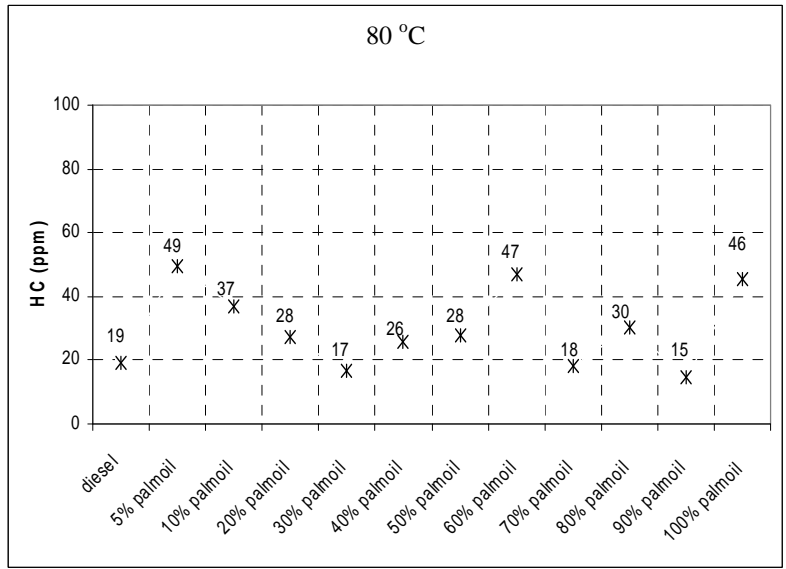

Fig. 22 The variation of $\mathrm{HC}$ when using mixtures of diesel-palm oil as fuel on $80^{\circ} \mathrm{C}$ fuel temperature, under max constant fuel consumption.

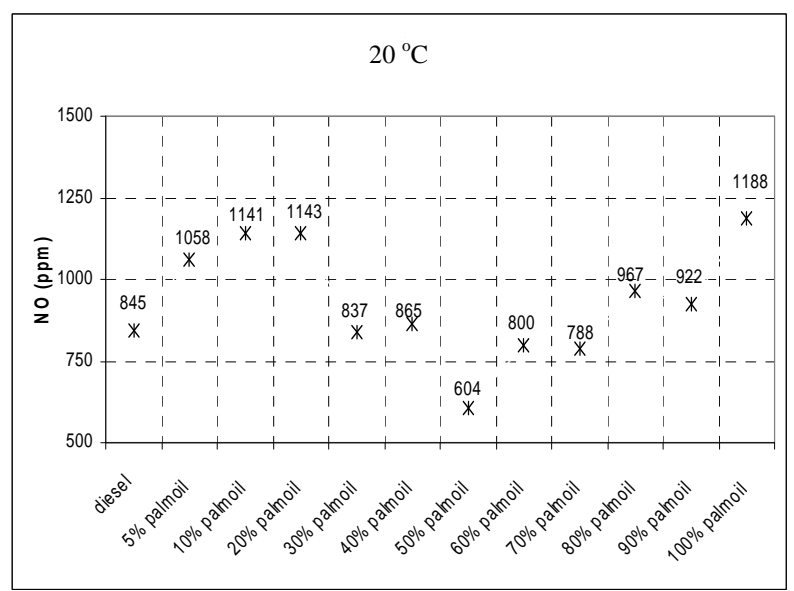

Fig. 23 The variation of NO when using mixtures of diesel-palm oil as fuel on $20^{\circ} \mathrm{C}$ fuel temperature, under max constant fuel consumption.

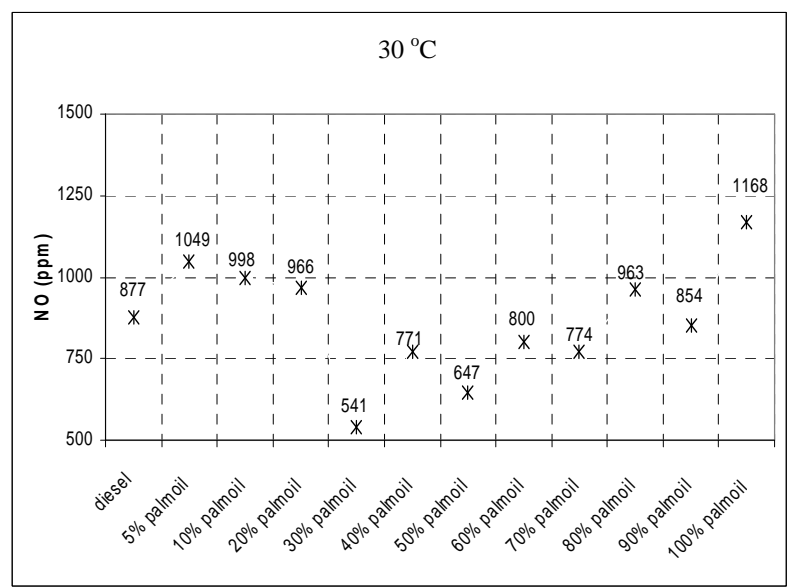

Fig. 24 The variation of NO when using mixtures of diesel-palm oil as fuel on $30^{\circ} \mathrm{C}$ fuel temperature, under max constant fuel consumption.

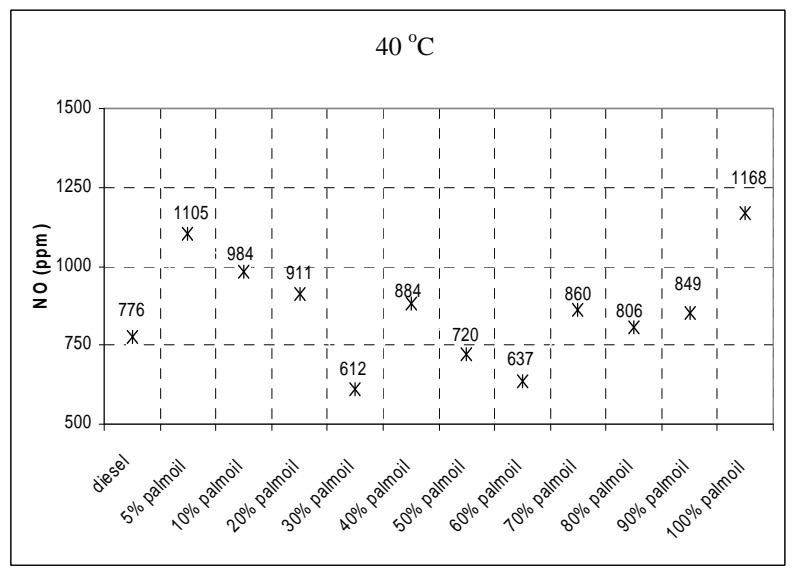

Fig. 25 The variation of NO when using mixtures of diesel-palm oil as fuel on $40{ }^{\circ} \mathrm{C}$ fuel temperature, under max constant fuel consumption.

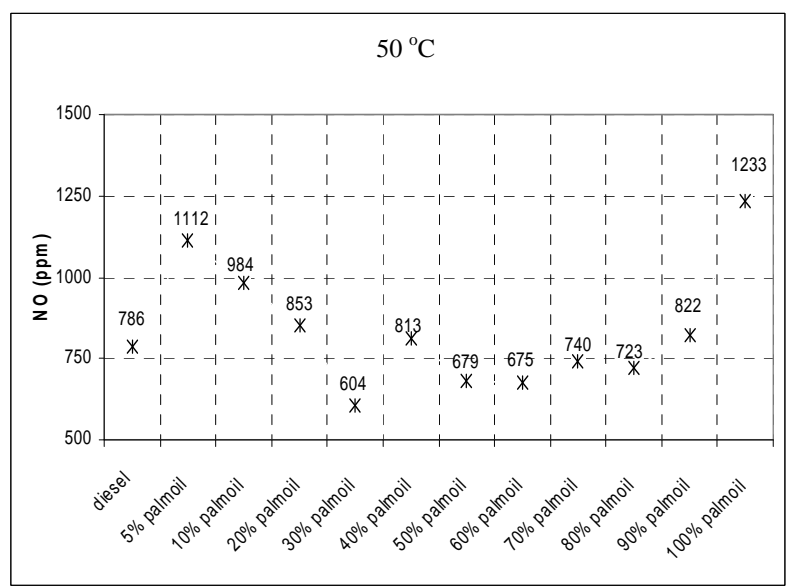

Fig. 26 The variation of NO when using mixtures of diesel-palm oil as fuel on $50{ }^{\circ} \mathrm{C}$ fuel temperature, under max constant fuel consumption.

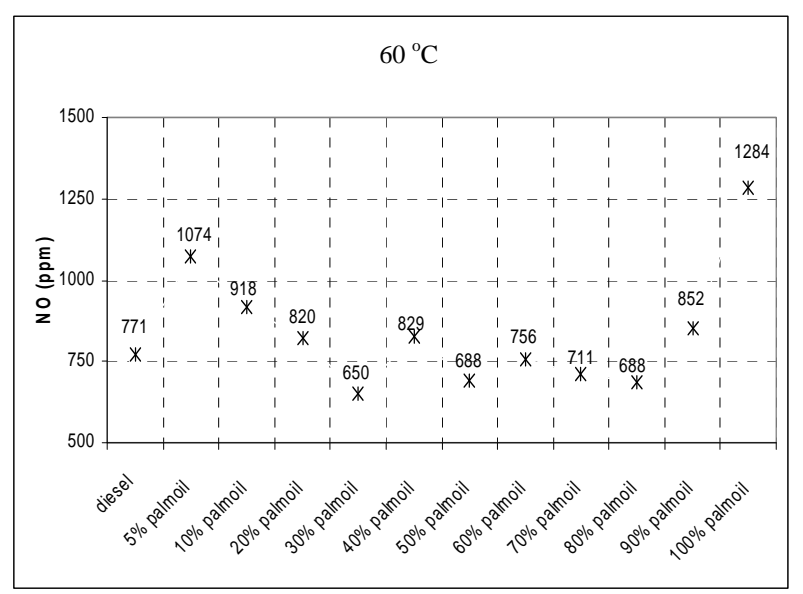

Fig. 27 The variation of NO when using mixtures of diesel-palm oil as fuel on $60{ }^{\circ} \mathrm{C}$ fuel temperature, under max constant fuel consumption. 


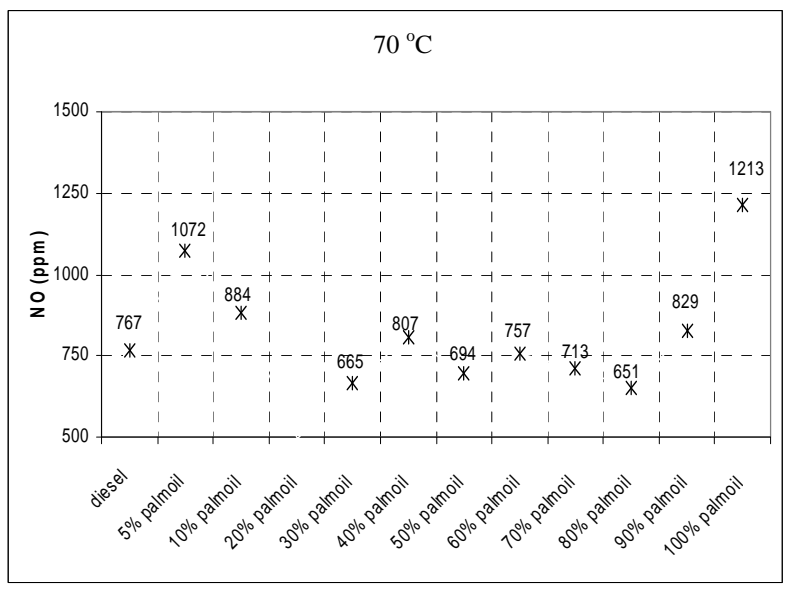

Fig. 28 The variation of NO when using mixtures of diesel-palm oil as fuel on $70^{\circ} \mathrm{C}$ fuel temperature, under max constant fuel consumption.

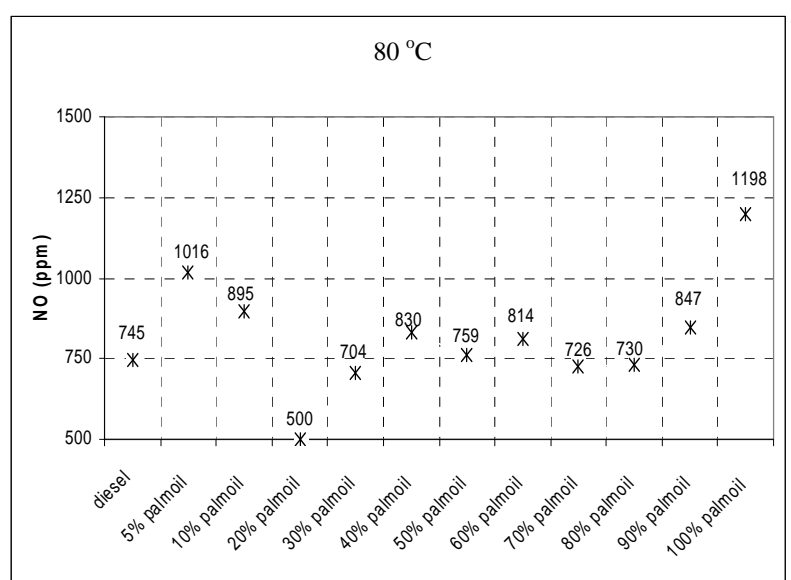

Fig. 29 The variation of NO variation when using mixtures of diesel-palm oil as fuel on $80^{\circ} \mathrm{C}$ fuel temperature, under max constant fuel consumption.

From Figs. 2-29, the following can be mentioned:

(1) For the mixture of fuels that have been used, it has observed stability in the number of turns (Figs. 2-8). Especially, diesel and plain palm oil appeared very little variation in rounds at different fuel temperatures. The lowest value of diesel (2,802 rpm) was measured when it was at $30{ }^{\circ} \mathrm{C}$ (Fig. 3) and the highest value (2,831 rpm) was observed at $50{ }^{\circ} \mathrm{C}$ (Fig. 5). In plain palm, the lowest value (2,736 rpm) was observed at the higher fuel temperature, while the highest value $(2,791$ rpm) was observed at $40{ }^{\circ} \mathrm{C}$ (Fig. 4). The highest average rounds (3,044 rpm) was observed at $20{ }^{\circ} \mathrm{C}$ (Fig. 2 ) in the fuel mixture of $20 \%$ of palm oil, while the lowest average rounds (2,765 rpm) was presented at 40
${ }^{\circ} \mathrm{C}$ (Fig. 4) in the fuel mixture of $60 \%$ of palm oil (Fig. 6). Generally, the fuel mixture of $20 \%$ palm oil appeared higher rounds in all temperatures, while the fuel mixture of $60 \%$ palm oil appeared lower rounds with an emphasis on lower temperatures $\left(20{ }^{\circ} \mathrm{C}, 30{ }^{\circ} \mathrm{C}\right.$ and $40{ }^{\circ} \mathrm{C}$ ).

(2) Higher CO emissions (Figs. 9-15) were observed at fuel mixtures of $5 \%$ and $10 \%$ of palm oil at all temperatures, while the fuel mixture of $20 \%$ of palm oil has the same $\mathrm{CO}$ emissions as the above mixtures but only up to the temperature of $60{ }^{\circ} \mathrm{C}$ (Fig. 13). At higher temperatures there is a noticeable drop in fuel emissions (Figs. 14 and 15). Diesel consistently generated too low emissions between $0.08 \%$ and $0.07 \%$, apart from $20{ }^{\circ} \mathrm{C}$ which is $0.10 \%$ (Fig. 8). Plain palm oil appears stability of emissions up to $40{ }^{\circ} \mathrm{C}$ (Fig. 11) and then there is a fall in emissions as the fuel temperature is increased resulting in $0.05 \%$ at $80{ }^{\circ} \mathrm{C}$, which was the lowest value that was observed (Fig. 15). The fuel mixture of $80 \%$ of palm oil has moderate emissions at lower fuel temperatures up to $50{ }^{\circ} \mathrm{C}$, while in higher temperatures the emissions were increased reaching the percentage of $0.20 \%$. The fuel mixture of $40 \%$ of palm oil appeared relatively high emissions between $0.16 \%$ and $0.18 \%$.

(3) HC emissions (Figs. 16-22) were lower at all fuel temperatures as well as diesel and fuel mixtures of $30 \%$ and $90 \%$ of palm oil. Very high emissions were observed in plain palm oil and in the fuel mixtures of $5 \%$ and $10 \%$ of palm oil. The remaining fuel mixtures gave emissions at moderate levels. The lowest value of emission (11 ppm) was observed at diesel at $20{ }^{\circ} \mathrm{C}$ fuel temperature (Fig. 16), while the highest value of emission (84 ppm) was observed in the fuel mixture of $10 \%$ of palm oil at $30{ }^{\circ} \mathrm{C}$ (Fig. 17).

(4) As far as NO emissions (Figs. 23-29) are concerned, it can mention that fuel temperature does not affect them. Almost all fuel mixtures that have been tested showed that emissions varied at the same level while fuel temperature was increasing. The only exception is the fuel mixture of $20 \%$ of palm oil, which 
began with the highest $\mathrm{NO}$ emissions (1,143 ppm) at 20 ${ }^{\circ} \mathrm{C}$ fuel temperature (Fig. 23) and then followed downward course as the fuel temperature was increasing, resulting in $500 \mathrm{ppm}$ at $80{ }^{\circ} \mathrm{C}$ (Fig. 29). From the remaining fuel mixtures it was observed that the mixture of $30 \%$ of palm oil had the lowest emissions (approximately $500 \mathrm{ppm}$ ), while the plain palm oil had the highest emissions (about 1200 ppm) at all fuel temperatures. In particular, higher emissions appeared in the fuel mixtures of $5 \%$ and $10 \%$ of palm oil, while relatively low emissions appeared in the fuel mixtures of $50 \%, 60 \%$ and $70 \%$ of palm oil.

\section{Conclusion}

In the majority of fuels that have been used, it observed stability in the number of turns. Especially diesel and plain palm oil appeared very little variation in turns at different fuel temperatures.

The lowest rates of carbon monoxide appeared in diesel fuel. Lower rates appeared in the fuel mixtures of $90 \%$ of palm oil as well. Similar are the results for the values of unburnt hydrocarbons. In higher turns the fuel mixtures of $30 \%, 40 \%$ and $50 \%$ of palm oil appeared better values.

Regarding the engine rpm, the change was small, while maintaining fuel consumption constant but changing the fuel temperature.

Finally, it needs to be considered that the viscosity of palm oil is greater than that of diesel. Thus when they are both in the same temperature, the performance of palm oil or any mixture of palm oil with diesel will be lower in the ignition of fuel.

\section{References}

[1] C. Arapatsakos, P. Sparis, Bioethanol-premium gasoline mixture tests in otto engines, in: International Conference of Combustion Institute, Athens, Greece, 1997.

[2] C. Arapatsakos, Testing a low output two stroke engine used for agricultural purposes using gasoline-bioethanol mixtures, in: Proceedings of the 5th International Conference of the Environmental Pollution, Thessaloniki, Greece, 2000.

[3] P. Hansson, B. Mattsson, Influence of derived operation-specific tractor emission data on results from an LCI on wheat production, The International Journal of Life Cycle Assessment 4 (1999) 202-206.

[4] C. Arapatsakos, The impact of ethanol as a fuel in the gas emissions, Journal of Environmental Science and Engineering 5 (2011) 771-775.

[5] C. Arapatsakos, A. Karkanis, P. Sparis, Gas emissions and engine behaviour when gasoline-alcohol mixtures are used, Environmental Technology 24 (2003) 1069-1077.

[6] R. Garofalo, EU biodiesel potential defining the opportunities, in: RSB Consultation Europe Stakeholder Outreach Meeting, EBB (European Biodiesel Board), Brussels, Mar. 19, 2009.

[7] C. Arapatsakos, K. Galanopoulos, T. Koutroumanidis, Catalyst temperature difference in relation to carbon monoxide emissions in a four-stroke engine, Journal of Engineering Technology 21 (2004) 52-55.

[8] P. Hájek, V. Olej, Air quality modelling by Kohonen's self-organizing feature maps and LVQ neural networks, WSEAS Transactions on Environment and Development 4 (2008) 90-95. 